\title{
Type-2 Fuzzy PID Controller Design for Mobile Robot
}

\author{
Min Seok Jie and Won Hyuk Choi \\ Department of Aeronautical System Engineering, Hanseo University Graduate, \\ Chungcheongnam-do, 357-953, Korea
}

\begin{abstract}
Autonomous driving of mobile robot is important in various working environments. For its autonomous driving, mobile robot utilized ultrasonic sensor to detect obstacles and avoid them. Also, there have been researches on supplementing function of avoiding crash by using control methods based on adoption of intellectual system. This research has designed type-2 fuzzy self-tuning PID controller which can enhance autonomous driving function of mobile robot under fixed obstacle environment. The fuzzy controller has utilized type-2 with multiple values and the fuzzy self-tuning PID controller adjusting gain value of PID controller is applied. 25 rules have been reduced to 9 rules to improve function of hardware. Type-2 fuzzy self-tuning PID controller is used to compare function of traditional PID controller and Type-1 fuzzy self-tuning PID controller. In terms of function of Type-2 fuzzy controller with reduced number of rules, it was confirmed through improvement in function of autonomous driving of mobile robot using MATLAB/Simulink.
\end{abstract}

Keywords: MATLAB/Simulink, Mobile robot, PID controller, Self-tuning controller, Type-2 fuzzy controller

\section{Introduction}

The robot has been improved with development of technology. The early robots were fixed to work hard and to increase the production. An autonomous mobile robot is intelligent robot that performs a given work with sensors by identifying the surrounded environment and reacts to the condition by itself instead of human. The mobile robot technology is a combination of sensing technology, controlling technology, information processing technology, machining processing technology, electronic technology, computer technology and many other technologies. The mobile robots have been researched to detect the obstacles and to avoid conflicts. The obstacle avoidance using artificial intelligence techniques is based on model, fuzzy logic, neural networks, genetic algorithms [2-3].

The PID controller is also used in a lot of simple designs of the control method. A control performance can be stable by using the PID controller. But it is not easy and intelligent to set appropriative parameters. In this paper, the fuzzy controller was used to improve the performance of autonomous mobile robots and complement the shortcomings of PID controller [5].

Previous research has developed a fuzzy controller to set the PID parameters [2]. According to the feedback error, the parameters are applied to PID controller and improve the speed, adaptability, accuracy of the control system. In this paper, the type-2 fuzzy selftuning PID controller is used to improve the performance of autonomous mobile robots. The Gain value of PID controller was tuned by type-2 fuzzy controller. Also, it reduced rules to reduce the load on the hardware. The performances of the type-1 fuzzy self-tuning PID controller and type-1 fuzzy self-tuning PID controller were compared and verified through MATLAB/Simulink. 


\section{The Mobile Robot System}

Used Pioneer 3DX robot is a two wheeled differential drive robot, where each wheel is driven independently. Forward motion is produced by both wheels driven at the same rate, turning right is achieved by driving the left wheel at a higher rate than the right wheel and vice versa for turning left. This type of mobile robot can turn on the spot by driving one wheel forward and second wheel backward at same rate. Third wheel is a castor wheel needed for mobile robot stability [11].

\subsection{Kinematic of the Mobile Robot}

The kinematic model of a mobile robot can be described as Figure 1. The reference coordinate system $(I)$ of the mobile $\operatorname{robot}\left(I_{p}\right)$ position can be expressed by

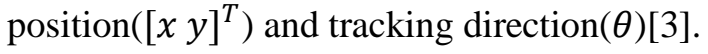

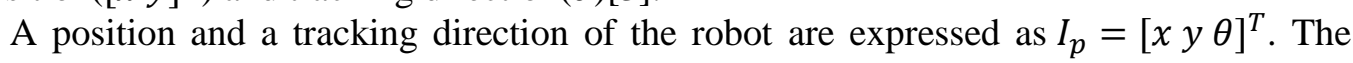
velocity of the robot is as following equation (1).

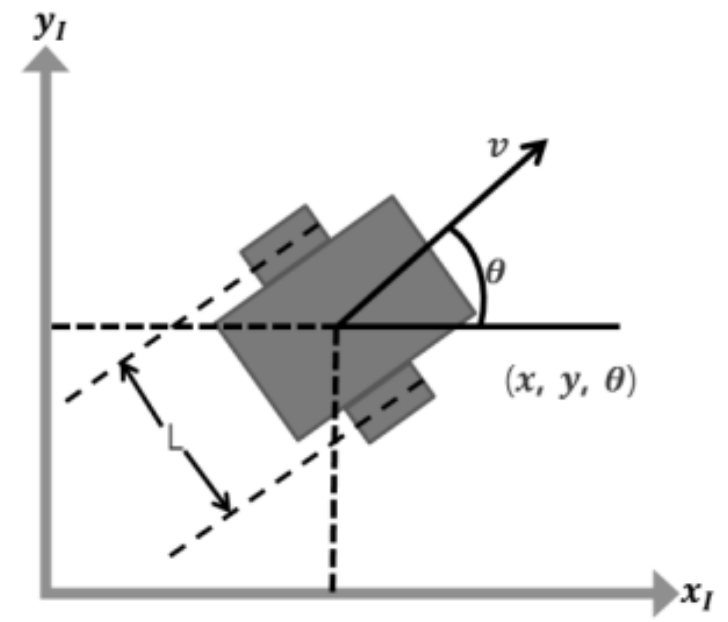

Figure 1. The Robot Kinematics Model

$$
{ }^{I} \dot{P}=[\dot{x} \dot{y} \dot{\theta}]
$$

In general, an attitude of the robot in reference coordinate system is expressed by an orthogonal rotation matrix. In the case of a mobile robot, driving on a plane is a rotation axis $z$. Based on the moving coordinate $\operatorname{system}(M)$, the rotation matrix in the reference coordinate $\operatorname{system}(I)$ is as the following equation(2)[7].

$$
{ }^{M} R_{I}=\left[\begin{array}{ccc}
\cos \theta & \sin \theta & 0 \\
-\sin \theta & \cos \theta & 0 \\
0 & 0 & 1
\end{array}\right]
$$

A wheels angular velocity and the linear velocity of the mobile robot are shown in Figure 2. $\mathrm{v}$ is linear velocity and $v_{R}, v_{L}$ are velocity of both wheels and $\mathrm{L}$ is distance of between both wheels. 


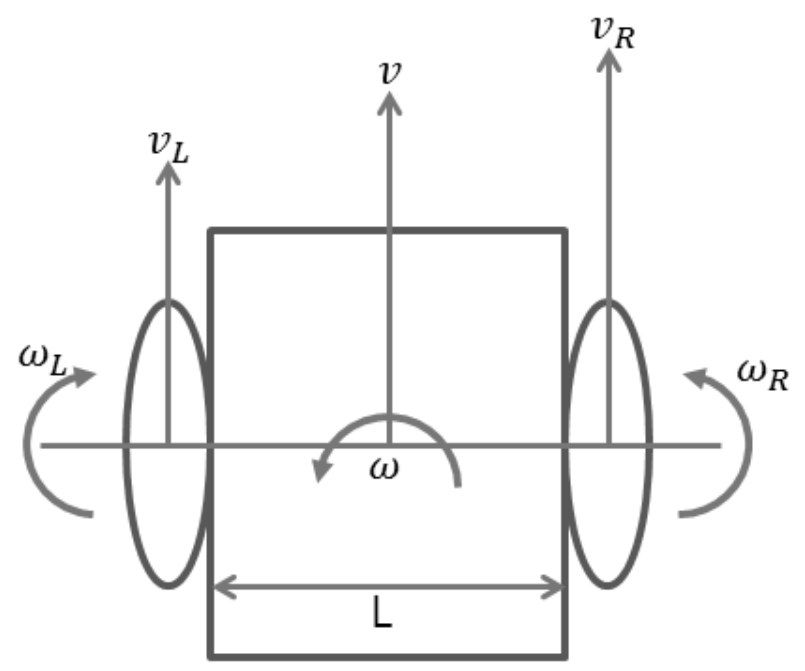

Figure 2. Angular Speed and Linear Velocity of Mobile Robot

The angular velocity in both wheels is expressed by $\omega_{L}$ and $\omega_{R}$. Under non-slipping conditions, velocity at the junction of two wheels and grounds is equation (3) [4].

$$
\begin{aligned}
& v_{R}=r \omega_{R} \\
& v_{L}=r \omega_{L}
\end{aligned}
$$

Velocity $(v(t))$ is as follows.

$$
v(t)=\left(v_{R}+v_{L}\right) / 2
$$

Angular speed $(\omega(t))$ is as follows.

$$
\omega(t)=\left(v_{R}-v_{L}\right) / L
$$

\subsection{Ultrasonic Sensor}

Pioneer $3 \mathrm{DX}$ is a mobile robot which has ultrasonic sensors. The data from ultrasonic sensors are the distance between the ultrasonic and object. The obstacle avoidance algorithm is based on the relative angle and distance between a robot and other objects. An autonomous mobile robot has sensors and the robot calculates the relative angle and distance.

Ultrasonic sensors have higher frequency band than the audio frequency that is used for measuring speed and position. Generation of ultrasonic wave is used in the vibration caused by the voltage or a magnetic field. Detection of the ultrasonic wave uses a device which converts sound pressure to electricity. [7-8].

The mobile robot is equipped with ultrasonic sensor to detect the obstacles. Equation (6) shows the central angle of sensor.

$$
\theta_{s}=140 / n-1
$$

Each sensor is installed in front of the mobile robot according to the central angle. An ultrasonic sensor mounted on the mobile robot is shown in Figure 3. 


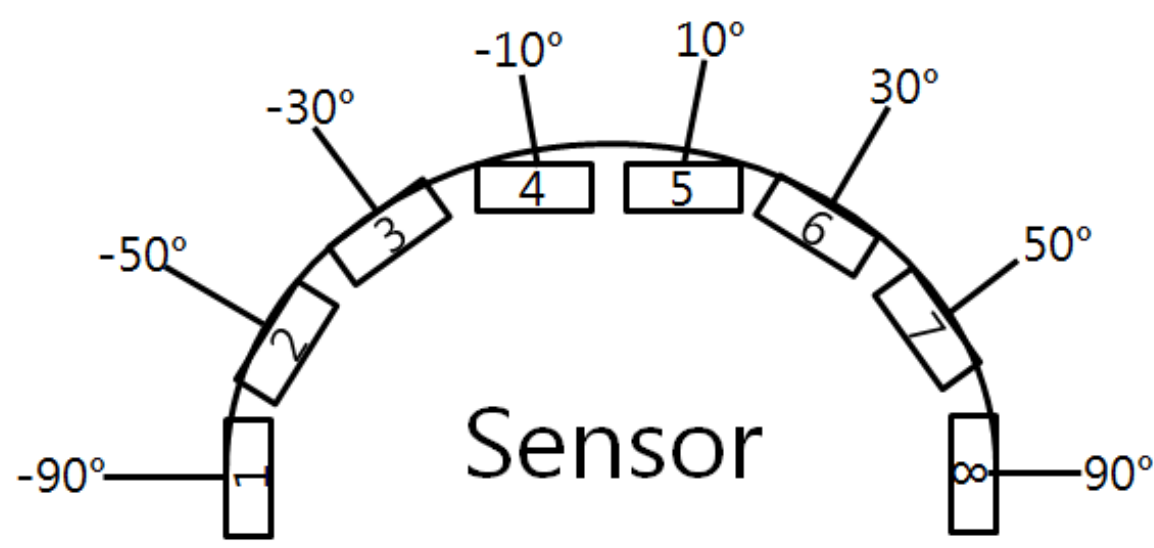

Figure 3. Sensor Part

The obstacle avoidance of a mobile robot is achieved through the eight sensors mounted on the front. According to the each sensor input, the rotation of the mobile robot is shown in Figure 4.

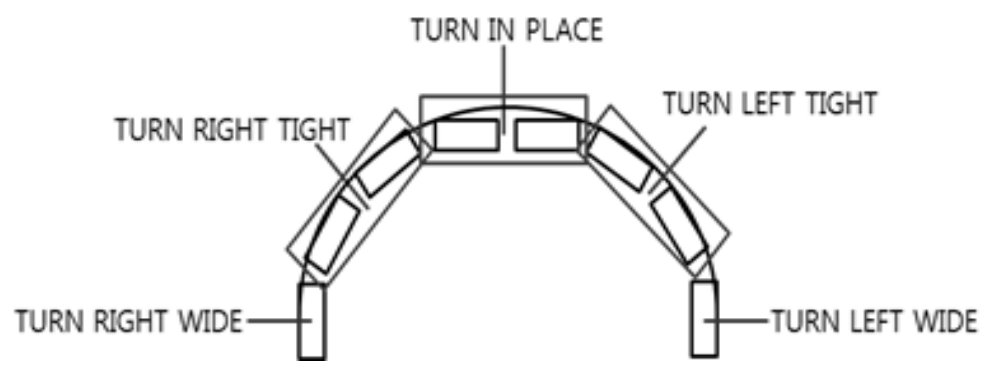

Figure 4. Avoidance Obstacle of Mobile Robot Use Ultrasonic Sensor

\section{Type-2 Fuzzy Logic Systems}

The fuzzy sets were presented by L.A Zadeh in 1965. The Fuzzy theory is mathematically established to make an uncertain value as a useful value. A type-2 fuzzy set, $\tilde{A}$, may be represented as :

$$
\tilde{A}=\left\{\left((x, u), \mu_{\tilde{A}}(x, u)\right) \mid \forall x \in X \quad \forall u \in J_{x} \subseteq[0,1]\right\}
$$

Where $\mu_{\tilde{A}}$ is the type-2 fuzzy membership function in which $0 \leq \mu_{\tilde{A}}(x, u) \leq 1$. $\tilde{A}$ can also be defined as:

$$
\tilde{A}=\int_{x \in X} \int_{u \in J_{x}} \mu_{\tilde{A}}(x, u) /(x, u) \quad J_{x} \subseteq[0,1]
$$

Where $\iint$ denotes union over all admissible $x$ and $u$.

$J_{x}$ is called primary membership of $x$. Additionally, there is a secondary membership value corresponding to each primary membership value that defines the possibility for primary memberships. Whereas the secondary membership functions can take values in the interval of $[0,1]$ in generalized type- 2 fuzzy logic systems, Since the general type-2 fuzzy logic systems are computationally very demanding, the use of interval type-2 fuzzy logic systems is more commonly seen in the literature, due to the fact that the computations are more manageable[10]. 


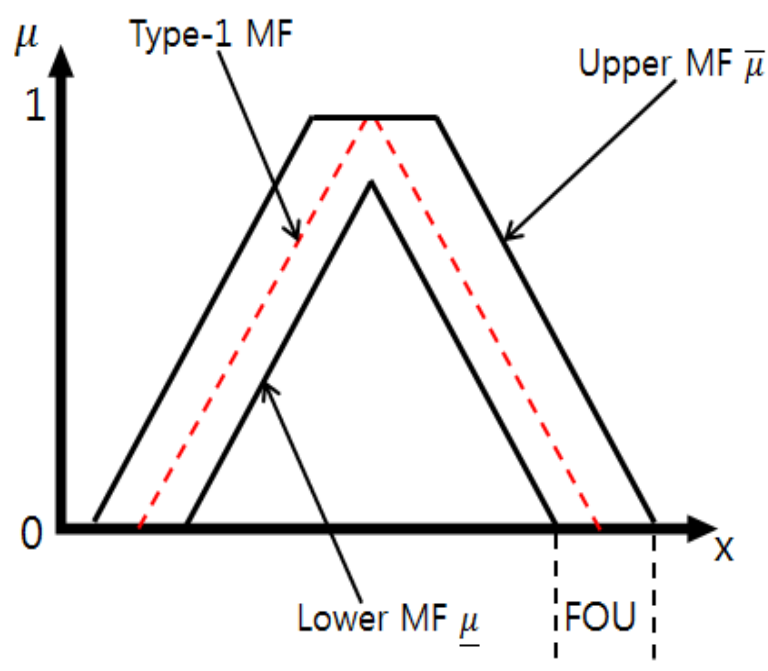

Figure 5. Type-2 Fuzzy Membership Function (FOU)

A type-2 fuzzy membership function is shown Figure 5.

A type-2 model can be described by fuzzy IF-THEN rules. The antecedent part is type2 fuzzy sets. In the consequent part, the structure is similar to that of type-1 fuzzy logic system, however, the parameters are type-1 fuzzy sets rather than numbers. In the Model, the rule base is as follows:

IF $x_{1}$ is $\tilde{A}_{j 1}$ and $x_{2}$ is $\tilde{A}_{j 2}$ and $\ldots$ and $x_{n}$ is $\tilde{A}_{j n}$ THEN $U_{j}=\sum_{i=1}^{n} W_{i j} x_{i}+B_{j}$

Where $x_{1}, x_{2}, \ldots, x_{n}$ are the input variable, $U_{j}$ 's are the output variable, $\tilde{A}_{j i}$ 's are type2 membership functions of $j^{t h}$ rule and $i^{t h}$ input. The parameters in the consequent part of the rule are $W_{i j}$ and $B_{j}(i=1, \ldots, n, j=1, \ldots, M)$ which are type-1 fuzzy sets. The final output of the first-order type-2 fuzzy logic system is as follows:

$$
\mathrm{U}\left(U_{1}, \ldots, U_{M}, F_{1}, \ldots F_{M}\right)=\int_{u_{1}} \cdots \int_{u_{M}} \int_{f_{1}} \cdots \int_{f_{M}} \tau_{j=1}^{M} \mu_{U_{j}}\left(u_{j}\right) * \tau_{j=1}^{M} \mu_{F_{j}}\left(f_{j}\right) / \frac{\sum_{j=1}^{M} f_{j} u_{j}}{\sum_{j=1}^{M} f_{j}}
$$

Where $\mathrm{M}$ is the number of rules fired, $u_{j} \in U_{j}, f_{j} \in F_{j}$, and $\tau$ and $*$ indicated the t-norm. $F_{j}$ is the firing strength which is defined as:

$$
F_{j}=\mu_{\tilde{A}_{j 1}}\left(x_{1}\right) \sqcap \mu_{\tilde{A}_{j 2}}\left(x_{2}\right) \sqcap \ldots \sqcap \mu_{\tilde{A}_{j n}}\left(x_{n}\right)
$$

Where $\Pi$ shows the meet operation.

$$
f(x)=u_{l}+u_{r} / 2
$$

Where $u_{r}$ and $u_{l}$ are the maximum and minimum values of $u$, respectively[10].

\section{Type-2 Fuzzy Self-Tuning PID Controller Design}

Type-1 fuzzy logic has a crisp output as a scalar value. Type-1 fuzzy logic includes fuzzifier rules, inference engine, and defuzzifier. Type-2 fuzzy logic is a type-1 fuzzy logic added to type-reducer. So type-2 fuzzy logic output is membership grade and crisp value. 


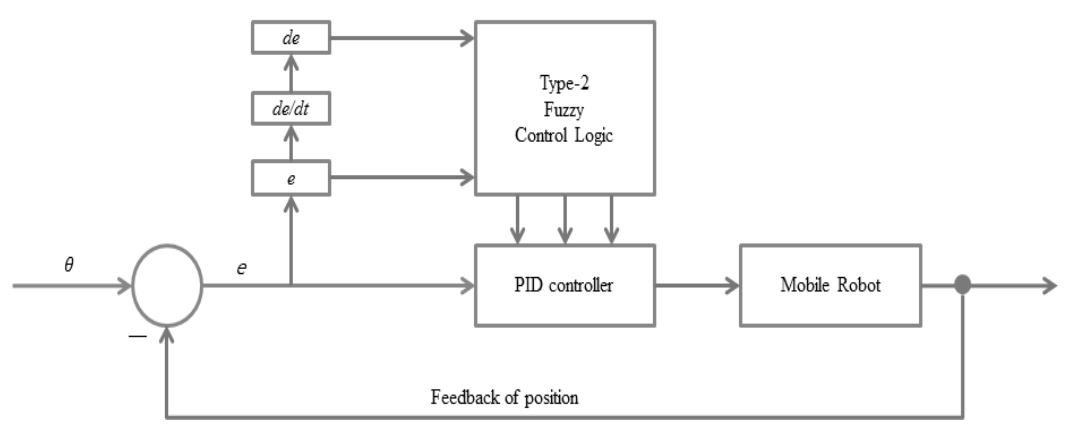

Figure 6. Structure of Fuzzy Self-Tuning PID Controller

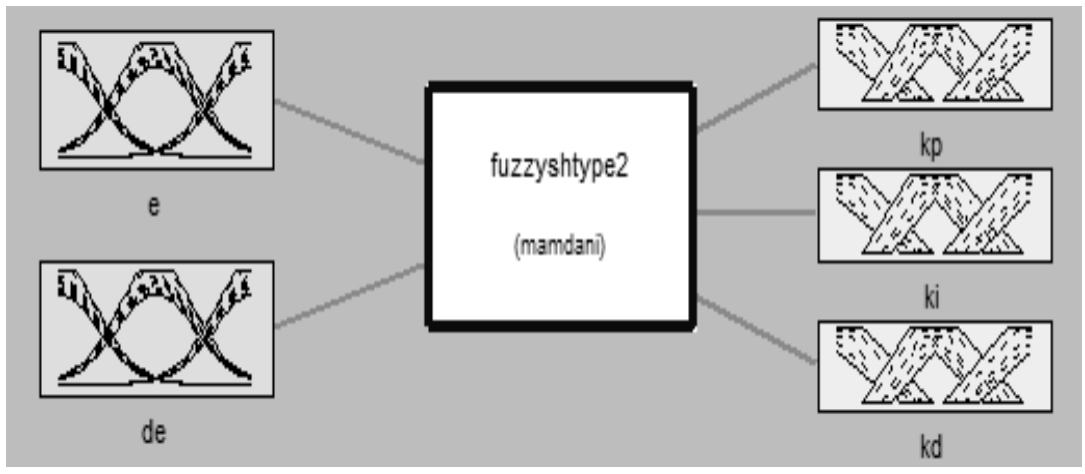

Figure 7. Type-2 Fuzzy Control Logic

As shown in Figure 6, fuzzy self-tuning PID controller receives input error $(e)$ and error rate $(\dot{e})$ to the input of the fuzzy controller [5]. Gain value of a PID controller is determined by the obtained output through the fuzzy controller [5].

Input variables of the fuzzy controller is the angular speed error $(e)$ and angular error rate $(\dot{e})$. The variable output of the fuzzy controller is the gain value a PID controller. A structure of type-2 fuzzy control logic is shown in Figure 7. The proposed controller is designed with MATLAB/Simulink [5].

Table 1. Fuzzy Rule Table (5×5)

\begin{tabular}{|c|c|c|c|c|c|c|}
\hline \multirow{2}{*}{\multicolumn{2}{|c|}{$K_{P} / K_{I} / K_{D}$}} & \multicolumn{5}{|c|}{ e } \\
\hline & & NB & NS & $\mathrm{ZE}$ & PS & PB \\
\hline \multirow{5}{*}{$\dot{e}$} & $\mathrm{NB}$ & $\mathrm{VB} / \mathrm{S} / \mathrm{S}$ & $\mathrm{VB} / \mathrm{B} / \mathrm{S}$ & $\mathrm{B} / \mathrm{B} / \mathrm{S}$ & $\mathrm{M} / \mathrm{B} / \mathrm{M}$ & $\mathrm{S} / \mathrm{S} / \mathrm{M}$ \\
\hline & NS & $\mathrm{VB} / \mathrm{M} / \mathrm{S}$ & $\mathrm{B} / \mathrm{B} / \mathrm{S}$ & $\mathrm{M} / \mathrm{B} / \mathrm{M}$ & $\mathrm{S} / \mathrm{B} / \mathrm{B}$ & $\mathrm{S} / \mathrm{M} / \mathrm{VB}$ \\
\hline & $\mathrm{ZE}$ & $\mathrm{S} / \mathrm{M} / \mathrm{VB}$ & $\mathrm{S} / \mathrm{B} / \mathrm{B}$ & $\mathrm{S} / \mathrm{VB} / \mathrm{B}$ & $\mathrm{S} / \mathrm{B} / \mathrm{B}$ & $\mathrm{S} / \mathrm{M} / \mathrm{VB}$ \\
\hline & PS & $\mathrm{S} / \mathrm{M} / \mathrm{B}$ & $\mathrm{S} / \mathrm{B} / \mathrm{B}$ & $\mathrm{S} / \mathrm{VB} / \mathrm{M}$ & $\mathrm{M} / \mathrm{B} / \mathrm{S}$ & $\mathrm{B} / \mathrm{M} / \mathrm{S}$ \\
\hline & $\mathrm{PB}$ & $\mathrm{M} / \mathrm{S} / \mathrm{S}$ & $\mathrm{B} / \mathrm{B} / \mathrm{S}$ & $\mathrm{VB} / \mathrm{VB} / \mathrm{S}$ & $\mathrm{VB} / \mathrm{B} / \mathrm{S}$ & $\mathrm{VB} / \mathrm{S} / \mathrm{S}$ \\
\hline
\end{tabular}


Table 2. Fuzzy Rule Table $(3 \times 3)$

\begin{tabular}{|c|c|c|c|c|}
\hline \multirow{2}{*}{$K_{P}$} & \multicolumn{3}{|c|}{$\mathrm{e}$} \\
\cline { 3 - 5 } \multicolumn{2}{|c|}{} & $\mathrm{S}$ & $\mathrm{M}$ & $\mathrm{B}$ \\
\hline \multirow{3}{*}{$\dot{e}$} & $\mathrm{~S}$ & $\mathrm{VB} / \mathrm{S} / \mathrm{S}$ & $\mathrm{B} / \mathrm{B} / \mathrm{S}$ & $\mathrm{M} / \mathrm{S} / \mathrm{S}$ \\
\cline { 2 - 5 } & $\mathrm{M}$ & $\mathrm{S} / \mathrm{M} / \mathrm{VB}$ & $\mathrm{B} / \mathrm{B} / \mathrm{B}$ & $\mathrm{S} / \mathrm{M} / \mathrm{VB}$ \\
\cline { 2 - 5 } & $\mathrm{B}$ & $\mathrm{M} / \mathrm{S} / \mathrm{S}$ & $\mathrm{B} / \mathrm{B} / \mathrm{S}$ & $\mathrm{VB} / \mathrm{S} / \mathrm{S}$ \\
\hline
\end{tabular}

A fuzzy rule base is used in order to obtain the optimized PID gain value. We use the 25 general rules in table 1 and 9 custumized rules in table 2 .

\section{Simulation}

We performed the simulation with MATLAB/Simulink and Solidworks. A Pioneer 3DX mobile robot was built using Solidworks. As shown in Figure 8, (a) is a part that implements the hardware of Pioneer 3DX using MATLAB/Simulink. (b) is a control unit which controls the angular velocity of the mobile robot. (c) is a section for outputting the results of the simulation visually. MATLAB/Simulink and Solidworks are linked so that we can check the movement of the mobile robot.

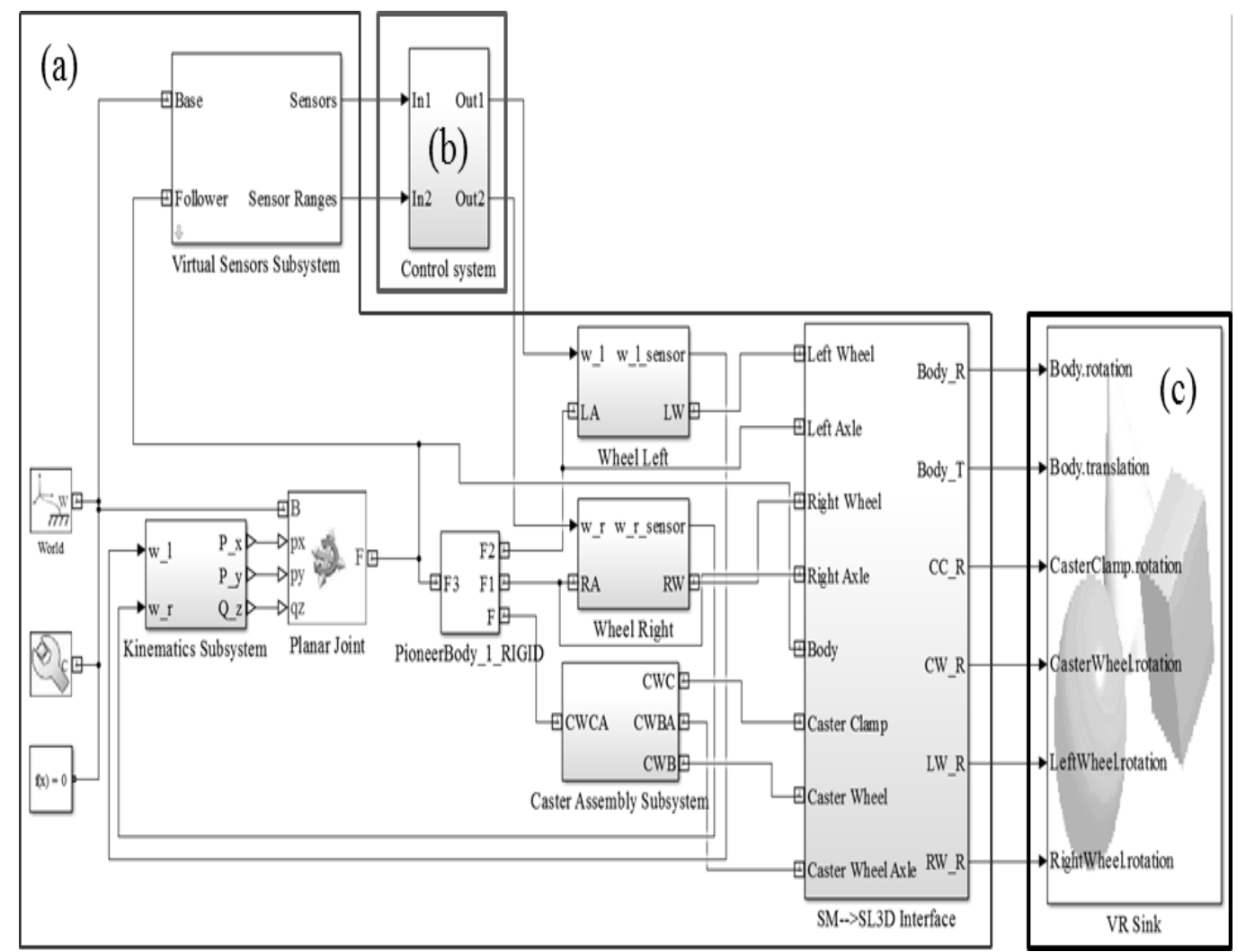

Figure 8. Pioneer 3DX Simulink Model

As shown in Figure 9, The Fuzzy Self-Tuning PID controller is designed to improve autonomous performance of mobile robot by MATLAB/Simulink. 


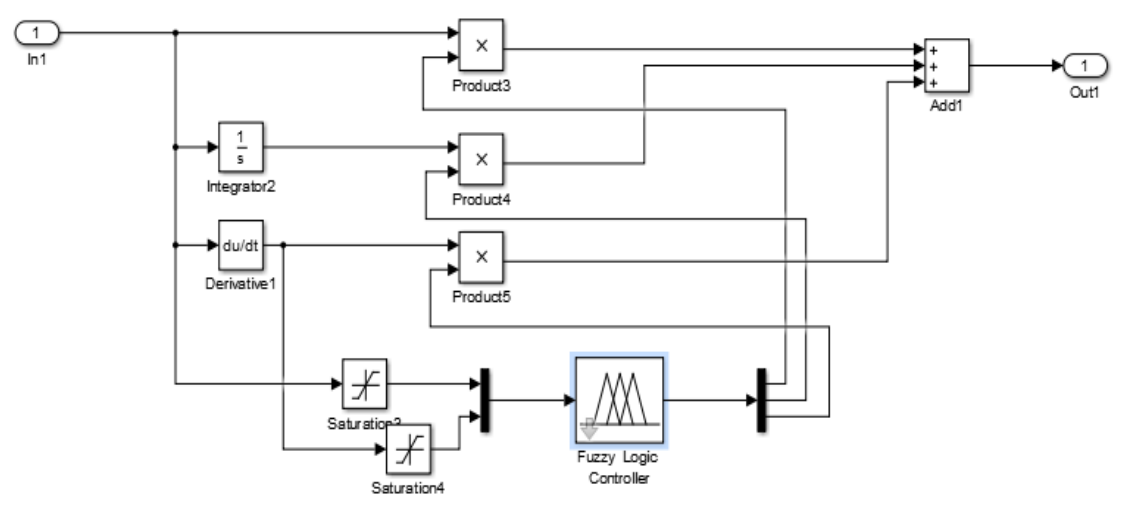

Figure 9. Fuzzy Self-tuning PID Controller MATLAB/Simulink Model

Simulation results are shown Figure 10. (a) is only using ultrasonic sensor. In the case of mobile robot using only ultrasonic sensors, there is a difficulty to exit the minimum point. In this paper, it was applied to design fuzzy self-tuning PID controller in order to complement these shortcomings. (b) is showing traveling route of a mobile robot equipped with a controller.

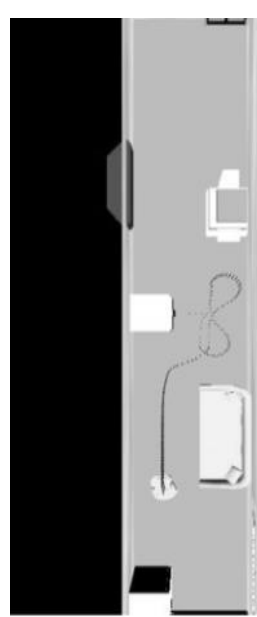

(a)

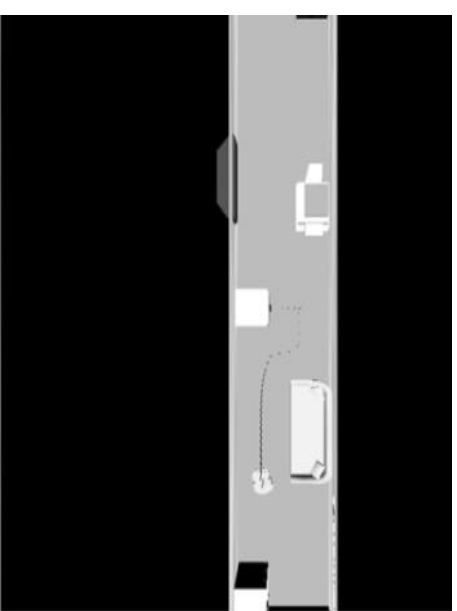

(b)

Figure 10. Simulation Results

\section{(a)Only Ultrasonic Sensor (b) Type-2 Fuzzy Self-Tuning PID Controller}

As shown in Figure 11, it indicates the direction of mobile robot using a type-1 fuzzy self-tuning PID controller. 


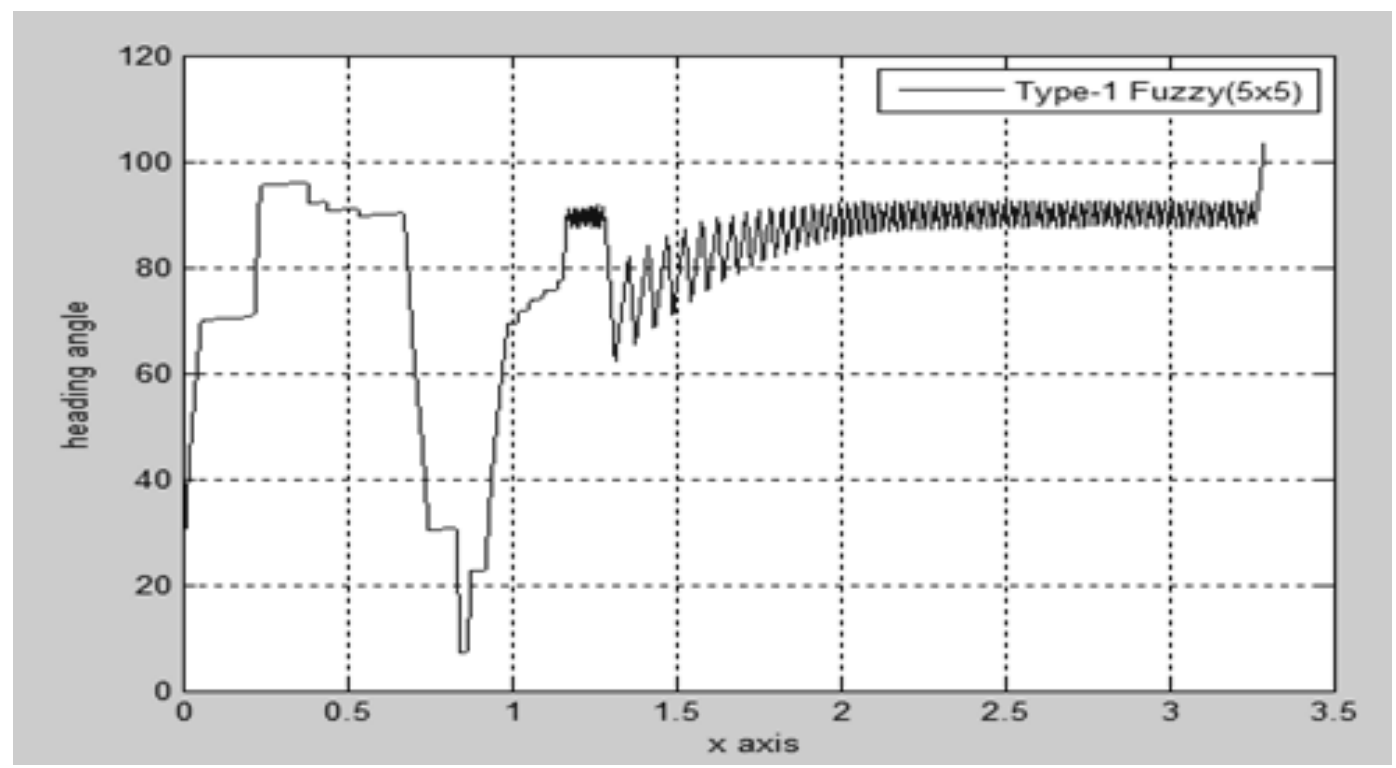

Figure 11. Type-1 Fuzzy Self-Tuning PID Controller Heading $(5 \times 5)$

As shown in Figure 12, it indicates the direction of the mobile robot using a type-2 fuzzy self-tuning PID controller. In comparison to Figure 10 and Figure 11, the type-2 fuzzy self-tuning PID controller is more stable than the type-1 fuzzy self-tuning PID controller when passing narrow area.

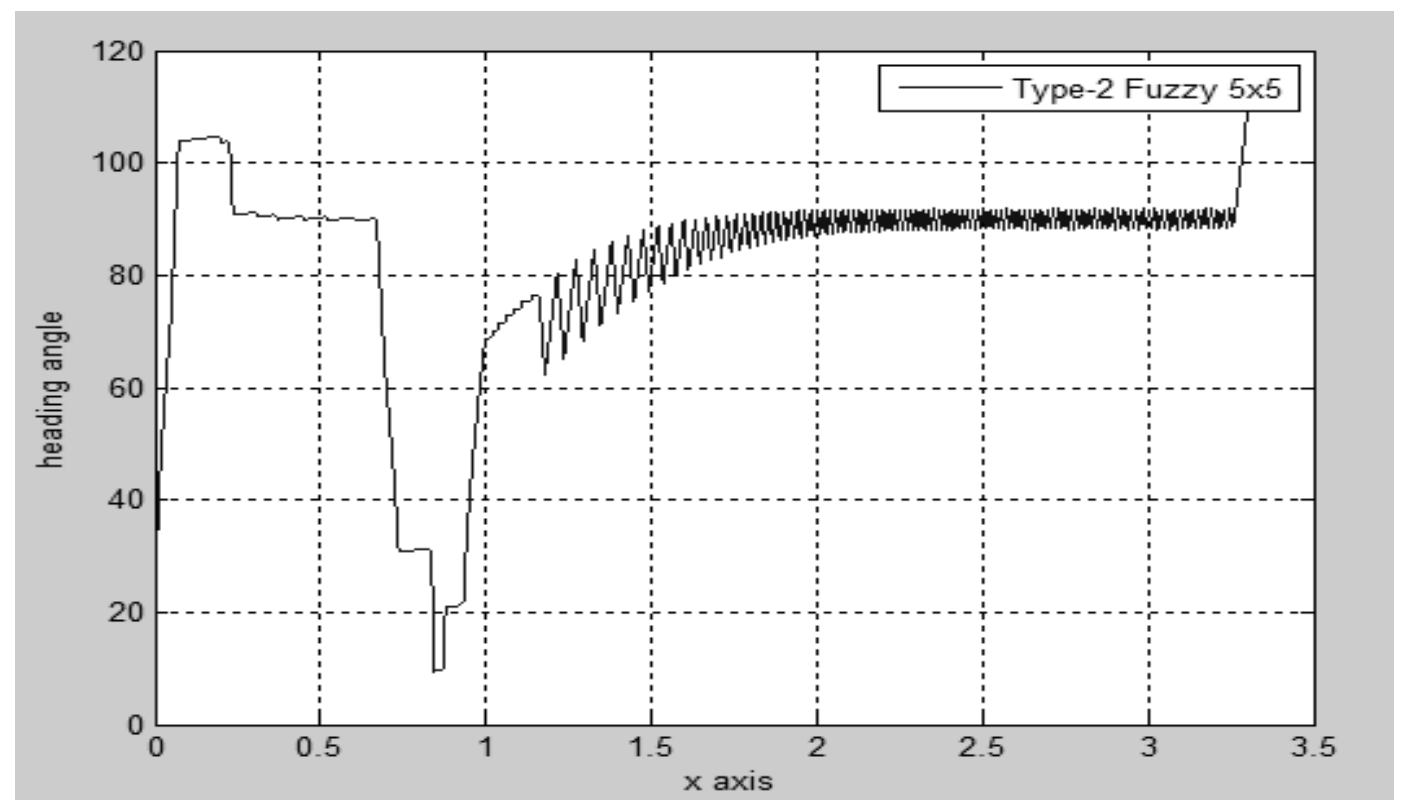

Figure 12. Type-2 Fuzzy Self-Tuning PID Controller Heading (5×5)

As shown in Figure 13, it indicates the direction of the mobile robot reduced from 25 to 9 in the type- 2 fuzzy rules. The type- 2 fuzzy self-tuning PID controller using 9 rules is less precise. So it can reduce the load of hardware. 


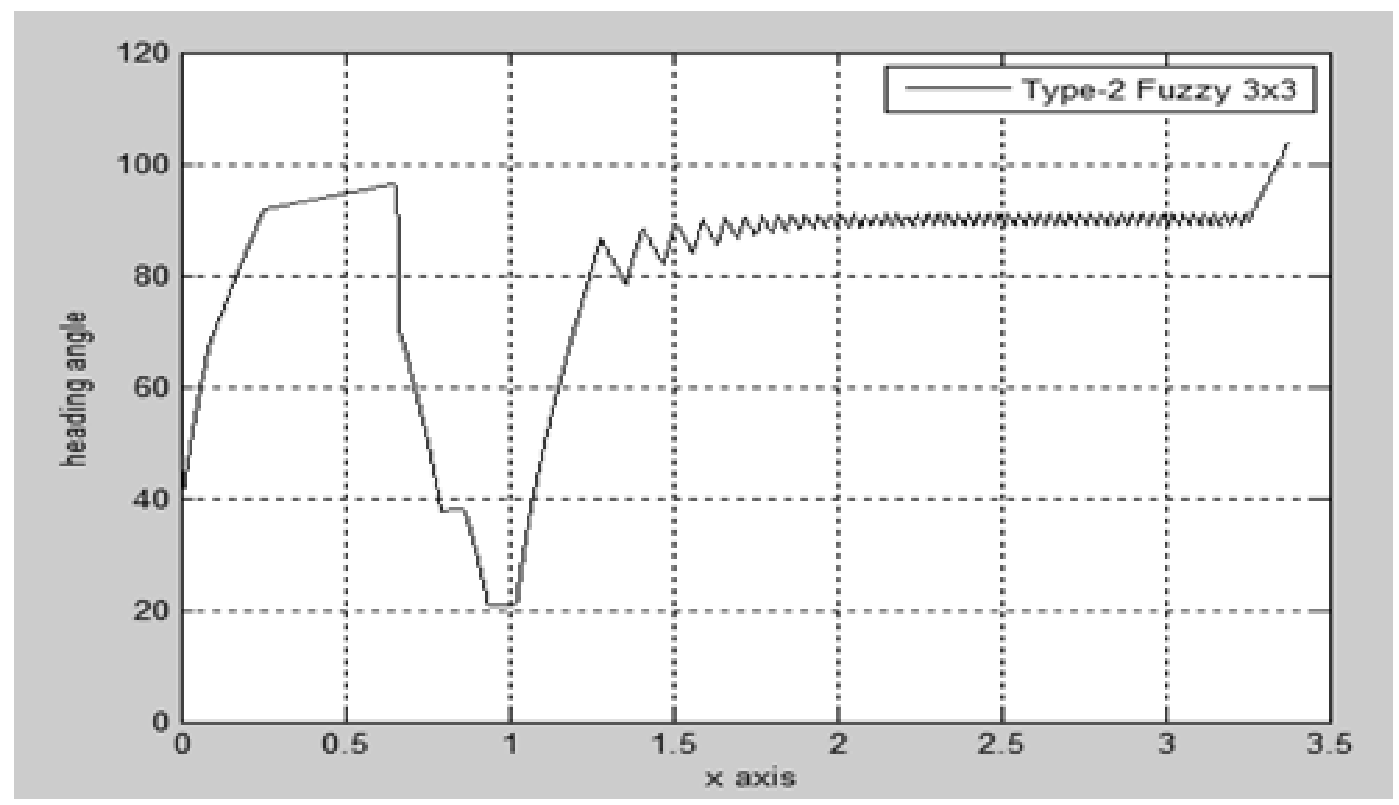

Figure 13. Type-2 Fuzzy Self-Tuning PID Controller Heading $(3 \times 3)$

\section{Conclusion}

In this paper, we propose a type-2 fuzzy self-tuning PID controller to improve the performance of autonomous mobile robots. Type-1 Fuzzy Self-Tuning PID controller makes up for the weak points of the PID controller and improves the autonomous performance of the mobile robot. Also, the proposed type-2 fuzzy self-tuning PID controller is superior to type-1 fuzzy self-tuning PID controller. We performed a simulation with the reduced fuzzy control rules to reduce load on the hardware.

The angular error and the error rate are the output PID gain through the fuzzy controller. An autonomous mobile robot using only ultrasonic sensors could not escape the minimum point easily. Type-2 fuzzy self-tuning PID controller has complemented the shortcomings and improved the autonomous performance. We confirmed the proposed controller through MATLAB/Simulink simulations.

\section{Acknowledgments}

This paper is a revised and expanded version of a paper entitled 'Advanced Science and Technology Letters' presented at 'The 5th International Conference on Information Science and Industrial Applications, Harbin, China, August 19-20’.

\section{References}

[1] S. H. Park, K. W. Kim W. H. Choi and M. S. Jie, "The Autonomous Performance Improvement of Mobile Robot using Type-2 Fuzzy Self-tuning PID Controller", Proceedings of the 5th International Conference on Information Science and Industrial applications, Harbin, China, (2016), August 19-20.

[2] Q. Xu, J.M. Kan, S.N. Chen and S.Q. Yan, "Fuzzy PID Based Trajectory Tracking Control of Mobile Robot and its Simulation in Simulink", International Journal of Control and Automation, vol. 7, no.8, (2014), pp. 233-244.

[3] H. R. Beom and H. S. Cho, "A Sensor-based navigation for a mobile robot using fuzzy-logic and reinforcement learning", IEEE Transaction on systems, man, cybernetics, vol. 12, no. 6, (1997), pp. 521527.

[4] D. K. Pratihar, K. Deb and A. Ghosh, "Fuzzy-Genetic Algorithms and Mobile Robot Navigation among Static Obstacles", IEEE Transaction on systems, man, cybernetics, (1999), pp. 327-333.

[5] L.A. Zadeh, "Fuzzy sets", Information and Control, vol. 8, (1965), pp. 338-353. 
[6] C. D. Jung, J. M. Kang and C. H. Park, "Study of Engine Oil Replacement Time Estimate Method using Fuzzy and Neural Network Algorithm in Ubiquitous Environment", International Journal of Control and Automation(IJCA), vol. 6, (2013), pp. 267--280.

[7] S. G. Lee, Y. T. Do, C. Y. Park and J. W. Lee, "Introduction to Robotics", SciTech, Seoul (2013).

[8] M. S. Chae, T. Y. Jung, S. B. Kang and T. K. Yang, "A Fuzzy Control of Autonomous Mobile Robot for Obstacle Avoidance", Journal of Korea Institute of Information and Communication Engineering, vol. 10, no. 9 , (2006), pp. 1718-1726.

[9] B. J. Choi and S. Jin, "Design of Simple-structured Fuzzy Logic System based Driving Controller for Mobile Robot",Journal of The Korean Institute of Intelligent Systems, vol. 22, no. 1, (2012), pp. 1-6.

[10] Q. Liang and J. M. Mendel, "Interval Type-2 Fuzzy Logic Systems: Theory and Design", IEEE Trans. On Fuzzy Systems, vol. 8, (2000), pp. 535-550.

[11] E. Ivanjko, T. Petrinić and I. Petrović, "Modelling of Mobile Robot Dynamics", Proceedings of the 7th EUROSIM Congrees on Modelling and Simulation vol. 2, Prague, Czech, (2010), September 06-10.
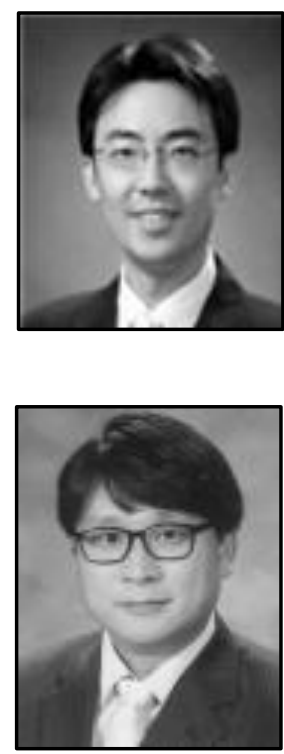

\section{Authors}

Min-Seok Jie, he received the $\mathrm{Ph} . \mathrm{D}$. degree in avionics from Korea Aerospace University, Korea. He was a Researcher of Intelligent Robot Research Center at Korea Institute of Science and Technology from 2007 to 2008. And he was a visiting professor at Purdue University from 2015 to 2016. Currently, he is Professor of avionics at Hanseo University, Korea, where he has been since 2008. His present research interests include robust control, robot vision, UAV.

Won-Hyuck Choi, he received the Ph.D. degree in avionics from Korea Aerospace University, Korea. He was a Professor of smart network at Doowon Technical University College, Korea. Currently, he is Professor of avionics at Hanseo University, Korea, where he has been since 2014. His present research interests include embedded system, home network 
International Journal of Control and Automation

Vol. 9, No. 11 (2016) 